\title{
Comparing Global Initiative for Asthma (GINA) criteria with the Childhood Asthma Control Test (C-ACT) and Asthma Control
} Test (ACT)

\author{
B.B. Koolen*, M.W.H. Pijnenburg" ${ }^{\#}$, H.J.L. Brackel ${ }^{\top}$, A.M. Landstra ${ }^{+}$, N.J. van den Berg $^{\S}$, \\ P.J.F.M. Merkus ${ }^{f}$, W.C.J. Hop ${ }^{\star \star}$ and A.A.P.H. Vaessen-Verberne*
}

ABSTRACT: Several tools are useful in detecting uncontrolled asthma in children. The aim of this study was to compare Global Initiative for Asthma (GINA) guidelines with the Childhood Asthma Control Test (C-ACT) and the Asthma Control Test (ACT) in detecting uncontrolled asthma in children.

145 children with asthma filled in a web-based daily diary card for 4 weeks on symptoms, use of rescue medication and limitations of activities, followed by either the C-ACT or ACT. For predicting uncontrolled asthma, score cut-off points of 19 were used for C-ACT and ACT.

According to GINA guidelines, asthma was uncontrolled in 71 (51\%) children and completely controlled in $19(14 \%)$ children. The area under the curve in the receiver operating characteristic curves for C-ACT and ACT versus GINA guidelines were 0.89 and 0.92 , respectively. Cut-off points of 19 for C-ACT and ACT resulted in a sensitivity of $33 \%$ and $66 \%$ in predicting uncontrolled asthma, respectively.

C-ACT and ACT correlate well with GINA criteria in predicting uncontrolled asthma, but commonly used cut-off points for C-ACT and ACT seem to underestimate the proportion of children with uncontrolled asthma as defined by GINA.

KEYWORDS: Asthma, asthma control, asthma control test, child, childhood asthma control test, Global Initiative for Asthma

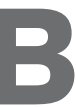
ased on recent asthma guidelines, like the Global Initiative for Asthma (GINA) guidelines, asthma treatment focuses on achieving and maintaining asthma control rather than on asthma severity [1-5]. A step-up in treatment is advised in order to achieve asthma control in uncontrolled patients. GINA guidelines state that "it is reasonable to expect that in most patients with asthma, control of the disease can and should be maintained." However, despite the availability of guidelines, a substantial proportion of adults as well as children with asthma is not optimally controlled [6-10].

Several tools have been developed to determine the level of control and to guide treatment [11-17]. Among them is the Asthma Control Test (ACT), which consists of five items and has been shown to be useful in the detection of poorly controlled asthma in adults and children aged $>12 \mathrm{yrs}$ [12]. More recently, a seven-item Childhood ACT (C-ACT) has been validated in children aged
$4-11$ yrs [14]. A score cut-off point $\leqslant 19$ was selected to indicate uncontrolled asthma for both questionnaires. The Asthma Control Questionnaire (ACQ) is perhaps the most used questionnaire worldwide and consists of seven items on symptoms, use of rescue medication and pulmonary function [11]. Moreover, a shortened version with five or six items has been validated [16]. Although the ACQ has recently been validated for use in children aged 6-16 yrs [17], there is limited experience with this questionnaire in children.

The C-ACT, ACT and ACQ have been used extensively in clinical trials. Despite definition of asthma control in GINA guidelines, the gold standard for determining asthma control in most studies was an estimation of the degree of asthma control by a physician [13, 14, 18-20]. In general, this estimation was based on a single outpatient visit $[13,14,18,20]$ and expressed in scores ranging from 1 (totally uncontrolled) to 5 (well controlled) $[13,14]$ or three groups of control
AFFILIATIONS

*Dept of Paediatrics, Amphia Hospital, Breda,

"Sophia Children's Hospital, Dept of Paediatric Pulmonology, Erasmus University Medical Centre,

**Dept of Biostatistics, Erasmus University Medical Centre, Rotterdam,

"Dept of Paediatrics, Catharina Hospital, Eindhoven,

${ }^{+}$Dept of Paediatrics, Rijnstate Hospital, Arnhem,

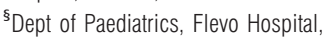
Almere, and

${ }^{f}$ Dept of Paediatric Pulmonology, Radboud University Nijmegen Medical Centre, Nijmegen, The Netherlands.

CORRESPONDENCE

A.A.P.H. Vaessen-Verberne

Dept of Paediatrics

Amphia Hospital

Langendijk 75

4819 EV Breda

The Netherlands

E-mail: avaessen-verberne@

amphia.nl

Received:

Nov 082010

Accepted after revision:

Jan 252011

First published online:

March 152011

European Respiratory Journa

Print ISSN 0903-1936

Online ISSN 1399-3003 
status (uncontrolled, partly controlled or controlled) [18, 20]. However, several studies have shown that both patients and their doctors tend to overestimate the level of control and the extent of improvement achieved with therapy [6-8, 10, 21, 22]. Four recently published studies compared the ACT or ACQ with asthma control as assessed by GINA guidelines [23-26]. Three of them included children aged $>12$ yrs $[23,25,26]$. Three studies used the ACQ [23, 24, 26] and one used the ACT [25].

Until now, no studies have been published comparing the C-ACT and ACT with GINA criteria in children. The aim of this study was to compare the results of the ACT and the CACT with GINA guidelines in detecting uncontrolled asthma in children.

\section{METHODS}

This prospective study is the extension of a study validating a web-based version of the C-ACT and ACT [27]. After completing three web-based or paper-based questionnaires, participants filled in a web-based daily diary card on symptoms, use of rescue medication and limitations of activities for a period of 4 weeks. At the end of this period they completed either the C-ACT (if aged 4-11 yrs) or the ACT (if aged $\geqslant 12$ yrs).

\section{Study population}

Children with asthma, treated in the outpatient clinics of four general hospitals and two university hospitals, were eligible for this study. Almost all children were treated with inhaled corticosteroids. Children, and parents of children in the younger age group (4-11 yrs), had to be able to speak the Dutch language and have Internet access at home. Children with lung diseases other than asthma were excluded from the study.

The study was approved by the medical ethical committees of the participating hospitals. All parents and children aged $\geqslant 12$ yrs signed an informed consent form before entering the study.

\section{Diary and GINA guidelines}

The web-based diary card was filled in once a day, in the afternoon or evening, during four consecutive weeks and was based on GINA criteria (table 1) [1]. In this study, slightly modified criteria were used, since lung function was not taken into account in assessing asthma control. Patients were allowed to fill in diary cards for the preceding 3 days. Diary cards contained questions on daytime symptoms, nocturnal symptoms, limitation of activity and use of rescue medication. Daytime symptoms such as coughing, wheezing and shortness of breath were scored on a scale from 0 (no complaints) to 3 (complaints during most of the day). In the same way, nocturnal symptoms such as coughing, wheezing and shortness of breath were scored from 0 (no complaints) to 3 (hardly any sleep due to respiratory symptoms). Limitation of activity ranged from 0 (no limitations) to 3 (severe limitation of activities) as well. Children and/or their parents could report the use of rescue medication as extra puffs taken.

Access to the web-based diary was granted by a personal account with username and password. After logging in to the secured Internet page, participants could answer the questions by clicking the appropriate box. After finishing the questions for a single day, results were submitted.

Control status in any week was assessed according to GINA criteria. An overall score was determined after 4 weeks, being the worst score of control status in any week. 5 completed diary days in 1 week was considered the minimum to include the week's data in the final assessment of asthma control.

\section{Childhood Asthma Control Test}

The C-ACT consists of seven items, addresses the previous 4 weeks and is divided into two parts [14]. One part is filled in by the child and consists of four questions on perception of asthma control, limitation of activities, coughing and awakenings at night. Each question has four response options. The second part is filled in by the parent or caregiver and consists of three questions (daytime complaints, daytime wheezing and awakenings at night) with six response options. The sum of all scores yields the C-ACT score, ranging from 0 (poorest asthma control) to 27 (optimal asthma control). A cut-off point $\leqslant 19$ indicates uncontrolled asthma [14].

\section{Asthma Control Test}

The ACT is a patient-completed questionnaire and consists of five items evaluating the preceding 4 weeks (limitation of activities, shortness of breath, awakenings at night, use of reliever medication and patient's perception of asthma control) $[12,13]$. Each question has five response options, resulting in scores of $1-5$. The sum of all scores yields the total ACT score, ranging from 5 (poorest asthma control) to 25 (optimal asthma

\section{TABLE 1 Control status according to Global Initiative for Asthma (GINA) guidelines}

Controlled

All of the below measures

None
None
None
None
Normal
None

None
Partly controlled

Any measure present in any week

$>2$ per week

Any

Any

$>2$ per week

$<80 \%$ predicted or personal best

$\geqslant 1$ per $y r$
Uncontrolled

$\geqslant 3$ features of partly controlled asthma present in any week

: forced expiratory volume in $1 \mathrm{~s}$ or peak expiratory flow; $\bullet:<3$ per week 


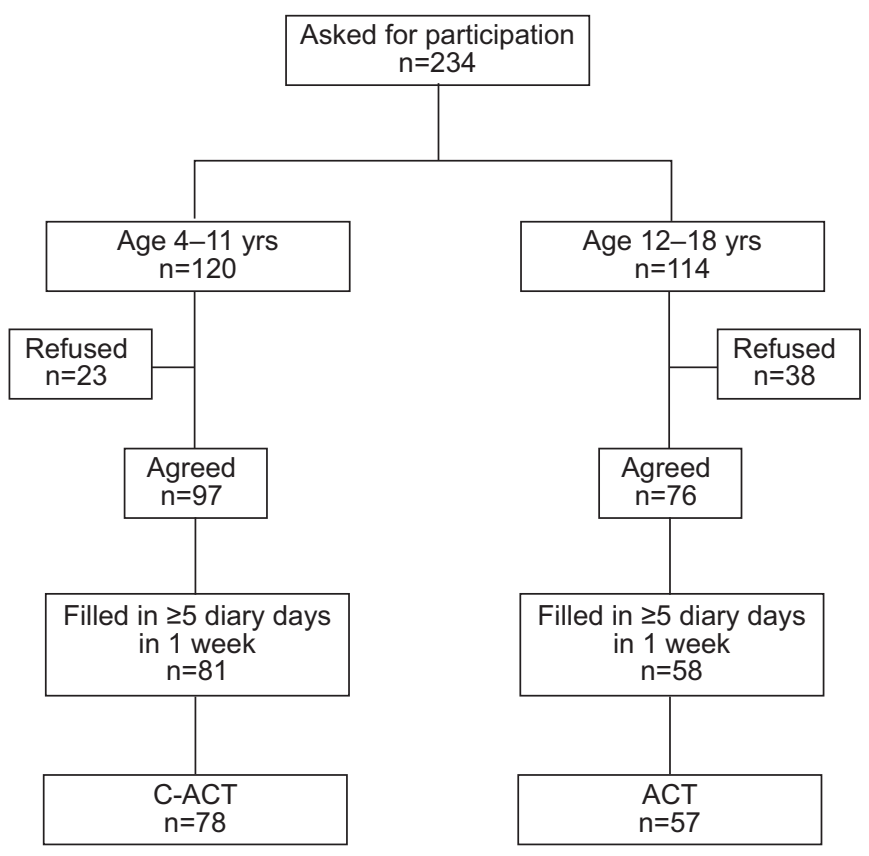

FIGURE 1. Flow chart of the study. ACT: Asthma Control Test; C-ACT: Childhood ACT.

control). It has been validated from the age of 12 yrs and a score $\leqslant 19$ indicates poorly controlled asthma.

In this study we used the Dutch version, translated by the MAPI-research institute in Lyon, France.

\section{Study protocol}

During a regular visit at the paediatric outpatient clinic, 234 children were asked to participate. 173 (74\%) children were prospectively included in the study, which was carried out between December 2008 and July 2009. After completing three web- or paper-based questionnaires, 145 participants proceeded into an extended study and filled in a web-based daily diary card, followed by the C-ACT or ACT. A flow chart of the study is shown in figure 1 .

\section{Statistical analysis}

The diagnostic value of the C-ACT and ACT to detect uncontrolled asthma as defined by GINA criteria was quantified by calculation of area under the curve (AUC) of receiver operating characteristic (ROC) curves. Sensitivity, specificity, positive predictive value, negative predictive value and percentage correctly classified were calculated for different cut-off points of C-ACT and ACT when compared with GINA criteria for uncontrolled asthma. The Chi-squared test was used to determine differences in GINA-defined control status between children with missing weeks and children with complete diaries. The Mann-Whitney U-test was used to compare ACT and C-ACT scores between control status groups according to GINA. A value of $p=0.05$ (two-sided) was the limit of statistical significance.

\section{RESULTS}

Out of 173 children included in the study, 145 children filled in the diary cards. The main reason for refusal to participate was

\begin{tabular}{|c|c|c|c|}
\hline \multirow[t]{2}{*}{ TABLE 2} & \multicolumn{3}{|c|}{$\begin{array}{l}\text { Baseline characteristics of } 145 \text { children who } \\
\text { completed at least one diary day }\end{array}$} \\
\hline & & Age 4-11 yrs & Age $12-18$ yrs \\
\hline Patients $\mathrm{n}$ & & 84 & 61 \\
\hline Age yrs & & $8.5 \pm 2.3$ & $13.9 \pm 1.5$ \\
\hline \multicolumn{4}{|l|}{ Sex } \\
\hline Male & & $54(64)$ & $36(59)$ \\
\hline Female & & $30(36)$ & $25(41)$ \\
\hline Duration of & sthma yrs & $4.7 \pm 2.9$ & $8.2 \pm 4.3$ \\
\hline \multicolumn{4}{|c|}{$\begin{array}{l}\text { Hospital admissions last year } \\
\text { per child }\end{array}$} \\
\hline 0 & & $78(93)$ & $56(92)$ \\
\hline 1 & & $5(6)$ & $3(5)$ \\
\hline 2 & & $1(1)$ & $2(3)$ \\
\hline \multicolumn{4}{|c|}{$\begin{array}{l}\text { Courses of oral steroids last year } \\
\text { per child }\end{array}$} \\
\hline 0 & & $76(91)$ & $53(87)$ \\
\hline 1 & & $5(6)$ & $3(5)$ \\
\hline 2 & & $3(4)$ & $4(7)$ \\
\hline 3 & & 0 & $1(2)$ \\
\hline Daily dose o & ICS $^{\#}$ & $400(200-500)$ & $400(200-500)$ \\
\hline \multicolumn{4}{|c|}{ Use of long-acting $\beta$-mimetics } \\
\hline No & & $60(71)$ & $19(31)$ \\
\hline Yes & & $24(29)$ & $42(69)$ \\
\hline \multicolumn{4}{|c|}{$\begin{array}{l}\text { Use of leukotriene receptor } \\
\text { antagonists }\end{array}$} \\
\hline No & & $74(88)$ & $49(80)$ \\
\hline Yes & & $10(12)$ & $12(20)$ \\
\hline FEV $1 \%$ prec & & $101.3 \pm 16.9$ & $96.6 \pm 12.9$ \\
\hline FenO ppb $^{\sigma^{\top}+}$ & & $12.0(7.9-18.9)$ & $17.2(10.1-32.0)$ \\
\hline \multicolumn{4}{|c|}{ 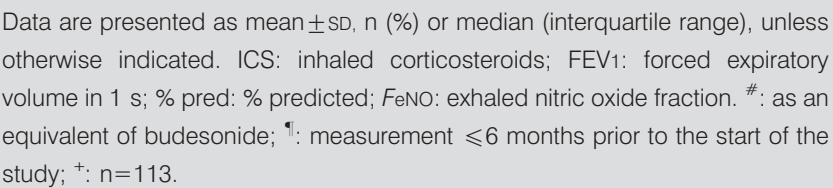 } \\
\hline
\end{tabular}

lack of interest, whereas one patient did not have Internet access. Baseline characteristics are shown in table 2. During the study period, no medication changes or exacerbations occurred in the study population. Children who failed to fill in their diaries did not differ in baseline characteristics from participants.

145 children completed at least 1 diary day. As the study period for the diary comprised 28 days, there were 4,060 possible diary days. At the end of the study, 3,266 (80\%) diary days were filled in. Out of 139 patients, 71 (51\%) had uncontrolled asthma in $\geqslant 1$ week. Of these 71 children, 25 children were uncontrolled in 1 week, 20 children were uncontrolled in 2 weeks, 12 children in 3 weeks and 14 children were uncontrolled in all 4 weeks. Only $19(14 \%)$ patients were classified as controlled, including seven children with missing weeks. There were no differences in GINA-defined control between children with missing weeks and children with complete diaries $(\mathrm{p}=0.713)$.

The median C-ACT score was 23 (interquartile range (IQR) 20.5-24), the median ACT score was 21 (IQR 18.5-24). Overall, $17 \%$ (13 out of 78 ) in the younger age group and 33\% (19 out of 


\begin{tabular}{lcccc}
\hline TABLE 3 & $\begin{array}{l}\text { Asthma Control Test (ACT) and Childhood ACT } \\
\text { (C-ACT) outcomes in relation to asthma control } \\
\text { according to Global Initiative for Asthma (GINA) } \\
\text { criteria }\end{array}$ \\
& $\begin{array}{c}\text { Age } \\
\text { 4-11 yrs }\end{array}$ & $\begin{array}{c}\text { C-ACT } \\
\text { score }\end{array}$ & $\begin{array}{c}\text { Age } \\
\mathbf{1 2 - 1 8} \text { yrs }\end{array}$ & $\begin{array}{c}\text { ACT } \\
\text { score }\end{array}$ \\
\hline GINA & & & & \\
Uncontrolled & $41(51)$ & $21(6-26)$ & $30(52)$ & $18(10-24)$ \\
Partially controlled & $26(32)$ & $23(20-27)$ & $23(40)$ & $23(20-25)$ \\
$\quad$ Controlled & $14(17)$ & $27(23-27)$ & $5(9)$ & $25(24-25)$ \\
Total & 81 & $23(6-27)^{\#}$ & 58 & $21(10-25)^{*}$ \\
\hline
\end{tabular}

Data are presented as $n(\%)$, median (range) or $n .{ }^{*}: n=78 ; \bullet: n=57$. All pairwise differences between the three GINA control categories regarding median values of C-ACT scores were significant (all $\mathrm{p}<0.002$ ). The same applied to the ACT scores.

$57)$ in the older age group had uncontrolled asthma corresponding to a C-ACT or ACT score $\leqslant 19$. Table 3 shows ACT and C-ACT outcomes in relation to asthma control according to GINA criteria.

Comparing C-ACT to GINA criteria for uncontrolled asthma resulted in an AUC of the ROC curve of 0.89 (95\% CI $0.82-$ 0.96). Using a cut-off point $\leqslant 19$ for detecting uncontrolled asthma with the C-ACT, this resulted in a sensitivity of $33 \%$ (13 out of 39) and a specificity of $100 \%$ (39 out of 39) for the C-ACT. When comparing the ACT to GINA criteria for uncontrolled asthma, we found an AUC of the ROC curve of 0.92 (95\% CI 0.84-0.99). For detecting uncontrolled asthma with the ACT, a cut-off point $\leqslant 19$ resulted in a sensitivity of $66 \%$ (19 out of 29 ) and a specificity of $100 \%$ (28 out of 28 ). ROC curves for C-ACT and ACT versus uncontrolled asthma according to GINA criteria are shown in figure 2. Excluding children with missing weeks resulted in an AUC of $0.89(95 \%$ CI $0.80-0.98)$ and 0.91 (95\% CI 0.81-1.00) for C-ACT $(n=47)$ and ACT $(n=36)$ in predicting uncontrolled asthma, respectively. Tables 4 and 5 show the performance of C-ACT and $\mathrm{ACT}$, respectively, in predicting uncontrolled asthma for different cut-off points.

Out of a total of 458 weeks with sufficient diary days, 157 weeks were classified as uncontrolled, 156 weeks as partially controlled and 145 weeks as controlled according to GINA criteria. Of 1,032 evaluable days in weeks with uncontrolled asthma, daytime symptoms occurred in 834 (81\%) days, limitation of activities in 641 (62\%) days, nocturnal symptoms in $573(56 \%)$ days and rescue medication in 553 (54\%) days. Of 1,015 evaluable days in weeks with partially controlled asthma, $289(28 \%)$ days were scored because of daytime symptoms, 285 (28\%) days because of limitation of activities, 178 (18\%) days because of the use of rescue medication and 88 (9\%) days were scored because of nocturnal symptoms. Children with a week of uncontrolled or partially controlled asthma failed on the characteristics of daytime symptoms and limitation of activities in particular. Surprisingly, rescue medication was not used as often as the amount of days with complaints.

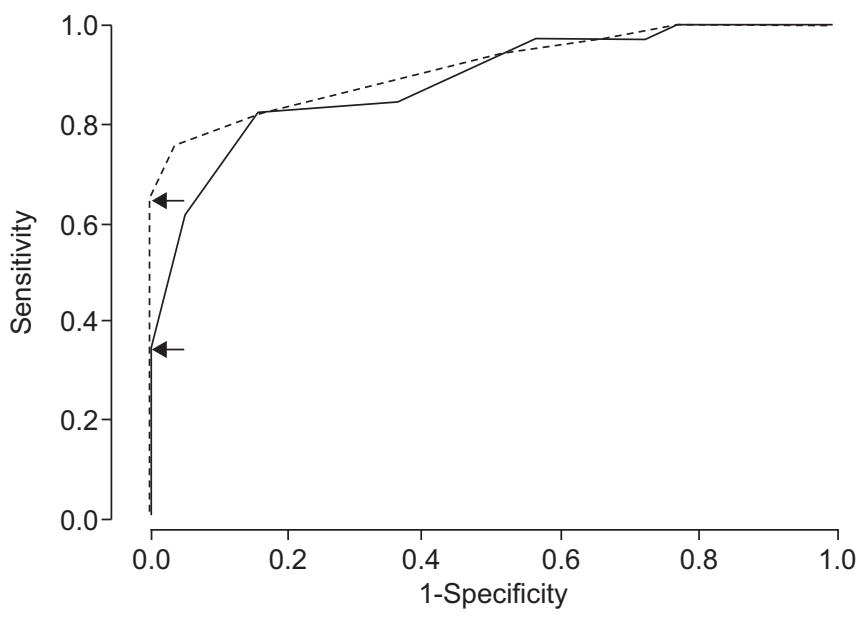

FIGURE 2. Receiver operating characteristic curves for Asthma Control Test (ACT) and Childhood ACT (C-ACT) to assess uncontrolled asthma according to Global Initiative for Asthma (GINA) criteria. — : C-ACT in children aged 4-11 yrs $(n=78)$; area under the curve (AUC) 0.89 (95\% Cl 0.82-0.96). Using a cut-off point of $\leqslant 19$ for C-ACT (lower arrow) results in a sensitivity of $33 \%$ (13 out of 39 ) and a specificity of $100 \%$ (39 out of 39 ) in predicting uncontrolled asthma. - - - -: ACT in children aged 12-18 yrs ( $\mathrm{n}=57)$; AUC 0.92 (95\% Cl 0.84-0.99). Using a cut-off point of $\leqslant 19$ for ACT (upper arrow) results in a sensitivity of $66 \%$ (19 out of 29 ) and a specificity of $100 \%$ (28 out of 28 ) in predicting uncontrolled asthma.

\section{DISCUSSION}

In this prospective study, we compared the results of the C-ACT and ACT with GINA criteria in predicting uncontrolled asthma. We found a good predictive value of both the C-ACT and the ACT for detecting uncontrolled asthma compared with GINA guidelines. Overall control status in this group of children, using questionnaires to determine the level of control, was acceptable. However, when GINA criteria were used to assess asthma control, a large proportion of children had uncontrolled asthma in $\geqslant 1$ out of 4 weeks (71 (51\%) out of 139 patients) when symptoms were scored. This high percentage of children with at least 1 week of uncontrolled asthma might possibly be explained by intercurrent infections, in particular as children were included during winter and spring and the majority had uncontrolled asthma in only 1 or 2 weeks.

Comparing the C-ACT and ACT with GINA criteria, we found excellent predictive values with AUC values of 0.89 and 0.92 , respectively. Using a cut-off point $\leqslant 19$ for both tests in predicting uncontrolled asthma, specificity for both tests was $100 \%$; however, sensitivity was low. As children with missing weeks were probably misclassified and overrated in their control status (in case missing weeks were uncontrolled weeks), in this study we might even have overestimated the sensitivity. This low sensitivity is remarkable and suggests that overestimation of asthma control by patients and/or their parents is considerable, as mentioned in previous publications $[6-8,10,21]$.

On the basis of the findings in this study, and presuming that GINA criteria are the gold standard for control status, one could argue that cut-off points for ACT as well as C-ACT should be increased. However, this study was not designed for validation of these questionnaires and the sample of included 


\begin{tabular}{|c|c|c|c|c|c|}
\hline \multirow{2}{*}{$\begin{array}{l}\text { TABLE } 4 \\
\text { Cut-off } \\
\text { point }\end{array}$} & \multicolumn{5}{|c|}{$\begin{array}{l}\text { Performance of the Childhood Asthma Control } \\
\text { Test (C-ACT) with various cut-off points as } \\
\text { compared with Global Initiative for Asthma (GINA) } \\
\text { criteria for assessing uncontrolled asthma in } 78 \\
\text { patients aged } 4-11 \text { yrs }\end{array}$} \\
\hline & $\begin{array}{c}\text { Sensitivity } \\
\%\end{array}$ & $\begin{array}{c}\text { Specificity } \\
\%\end{array}$ & $\begin{array}{l}\text { PPV } \\
\%\end{array}$ & $\begin{array}{c}\text { NPV } \\
\%\end{array}$ & $\begin{array}{c}\text { Correctly } \\
\text { classified \% }\end{array}$ \\
\hline$\leqslant 17$ & 18 & 100 & 100 & 55 & 59 \\
\hline$\leqslant 18$ & 23 & 100 & 100 & 57 & 62 \\
\hline$\leqslant 19$ & 33 & 100 & 100 & 60 & 67 \\
\hline$\leqslant 20$ & 49 & 97 & 95 & 66 & 73 \\
\hline$\leqslant 21$ & 62 & 95 & 92 & 71 & 78 \\
\hline$\leqslant 22$ & 82 & 85 & 84 & 83 & 83 \\
\hline$\leqslant 23$ & 85 & 64 & 70 & 81 & 74 \\
\hline$\leqslant 24$ & 97 & 44 & 63 & 94 & 71 \\
\hline
\end{tabular}

PPV: positive predictive value; NPV: negative predictive value

\begin{tabular}{|c|c|c|c|c|c|}
\hline \multirow{2}{*}{$\begin{array}{l}\text { TABLE } 5 \\
\text { Cut-off } \\
\text { point }\end{array}$} & \multicolumn{5}{|c|}{$\begin{array}{l}\text { Performance of the Asthma Control Test (ACT) } \\
\text { with various cut-off points as compared with } \\
\text { Global Initiative for Asthma (GINA) criteria for } \\
\text { assessing uncontrolled asthma in } 57 \text { patients } \\
\text { aged 12-18 yrs }\end{array}$} \\
\hline & $\begin{array}{c}\text { Sensitivity } \\
\%\end{array}$ & $\begin{array}{c}\text { Specificity } \\
\%\end{array}$ & $\begin{array}{c}\text { PPV } \\
\%\end{array}$ & $\begin{array}{c}\text { NPV } \\
\%\end{array}$ & $\begin{array}{c}\text { Correctly } \\
\text { classified \% }\end{array}$ \\
\hline$\leqslant 17$ & 45 & 100 & 100 & 64 & 72 \\
\hline$\leqslant 18$ & 55 & 100 & 100 & 68 & 77 \\
\hline$\leqslant 19$ & 66 & 100 & 100 & 74 & 82 \\
\hline$\leqslant 20$ & 76 & 96 & 96 & 79 & 86 \\
\hline$\leqslant 21$ & 86 & 75 & 78 & 84 & 81 \\
\hline$\leqslant 22$ & 90 & 64 & 72 & 86 & 77 \\
\hline$\leqslant 23$ & 93 & 54 & 68 & 88 & 74 \\
\hline$\leqslant 24$ & 100 & 21 & 57 & 100 & 61 \\
\hline
\end{tabular}

PPV: positive predictive value. NPV: negative predictive value. patients is too small for such an exercise. A limitation in our study is that we failed to systematically rate the control status by the treating paediatrician. This would have been of special interest as a large proportion of children was classified as uncontrolled by GINA criteria. According to GINA guidelines this would have had the implication of augmenting treatment, usually by increasing inhaled corticosteroid doses. It also raises the question of whether the GINA criteria are too strict, as from a clinical point of view those children with 1 week uncontrolled asthma, due to a short increase in symptoms in a viral infection period, will usually not be treated that way. However, in daily practice, GINA criteria will usually not be based on diary cards but on reporting symptoms, thus are likely to be underreported [7]. A second limitation of this study is that we included no follow-up period, so we cannot report on the value of (C)-ACT as a predictor of future exacerbations, which might be an additional aspect of control status.

Most studies use doctor's rating as the gold standard for assessing asthma control and only a few studies assessed asthma control according to GINA criteria. The first study using GINA criteria was published in 2006 by JUNIPER et al. [23], comparing ACQ with GINA criteria in patients aged 12-80 yrs. Modified GINA criteria were used to determine the optimal cut-off point for the ACQ and a correlation of 0.76 (no p-value) for ACQ and GINA criteria was found. The second study by VAN DEN NIEUWENHOF et al. [24] investigated the correlation of ACQ and GINA criteria in adults. Out of 108 asthma patients, $20 \%$ was defined as poorly controlled and $53 \%$ as very poorly controlled according to GINA criteria in a 4-week registration period. An optimal sum score cut-off value of 4 points for ACQ in discriminating between well/moderately controlled asthma and poorly/very poorly controlled asthma was found. A third study using GINA criteria by THOMAS et al. [25] compared ACT with GINA criteria in almost 3,000 patients aged $\geqslant 12$ yrs. Asthma control was defined according to modified GINA criteria from single patient and physician response forms with reference to the previous 4 weeks. $68 \%$ of patients had uncontrolled asthma according to GINA criteria. The AUC of the ROC curve for ACT was 0.84 . Using a cut-off point $\leqslant 19$ in predicting uncontrolled or partly controlled asthma, they found a sensitivity of $60 \%$ and a specificity of $92 \%$, which is comparable to our data. Recently, O'BYRNE et al. [26] compared three classification systems on asthma control (GINA criteria, Gaining Optimal Asthma Control (GOAL) criteria and ACQ) in a large group of patients aged $\geqslant 12$ yrs $(n=8,188)$. GINA and GOAL criteria agreed very well and GINA controlled/partly controlled and GOAL totally controlled/well controlled correlated with an ACQ-5 score $<1$.

In conclusion, C-ACT and ACT compared with GINA guidelines demonstrate good agreement. However, applying GINA criteria resulted in a large proportion of children with uncontrolled asthma for $\geqslant 1$ out of 4 weeks. With commonly used cut-off points of C-ACT and ACT $(\leqslant 19)$, a fairly large proportion of children is considered controlled, although GINA criteria suggest that they are uncontrolled for $\geqslant 1$ out of 4 weeks. Specificity in detecting uncontrolled asthma was high, but sensitivity was low. Therefore, C-ACT and ACT using generally used cut-off points might underestimate the proportion of children with uncontrolled asthma. Further studies in children are necessary to compare different control measurements with doctor's rating of control status and study the predictive value for future exacerbations.

\section{SUPPORT STATEMENT}

A.A.P.H. Vaessen-Verberne received an unrestricted research grant from GlaxoSmithKline Pharmaceuticals and Consumer Healthcare (Zeist, the Netherlands) for developing web-based versions of C-ACT and ACT.

\section{STATEMENT OF INTEREST}

Statements of interest for H.J.L. Brackel and A.A.P.H. Vaessen-Verberne can be found at www.erj.ersjournals.com/site/misc/statements.xhtml

\section{ACKNOWLEDGEMENTS}

We gratefully thank the involved paediatric asthma nurses and medical students for their help and active guidance throughout the study: D. Stevens-Blijlevens, D. de Hond and A. van Limpt (Amphia Hospital, Breda), M. Lagendijk (Erasmus University Medical Centre, Rotterdam), C. Linssen-Geven (Catharina Hospital, Eindhoven), L. van 
Gilst and H. Gerrits (Rijnstate Hospital, Arnhem), G. van der Zande (Flevo Hospital, Almere) and M. Bobbert (Radboud University Medical Centre, Nijmegen, all the Netherlands).

\section{REFERENCES}

1 Global Initiative for Asthma. Global Strategy for Asthma Management and Prevention. Available from www.ginasthma. org Date last updated: December 2009. Date last accessed: March 20, 2010.

2 Graham LM. Classifying asthma. Chest 2006; 130: Suppl. 1, 13S$20 \mathrm{~S}$.

3 Bateman ED, Hurd SS, Barnes PJ, et al. Global strategy for asthma management and prevention: GINA executive summary. Eur Respir J 2008; 31: 143-178.

4 Astma bij kinderen [Asthma in children]. www.nvk.pedianet.nl/ pdfs/200810_astma_bij_kinderen.pdf Date last updated: April 27, 2009. Date last accessed: March 20, 2010.

5 Expert Panel Report 3 (EPR3): Guidelines for the Diagnosis and Management of Asthma. www.nhlbi.nih.gov/guidelines/ asthma/asthgdln.htm Date last updated: August 5, 2008. Date last accessed: March 20, 2010.

6 Rabe KF, Vermeire PA, Soriano JB, et al. Clinical management of asthma in 1999: the Asthma Insights and Reality in Europe (AIRE) study. Eur Respir J 2000; 16: 802-807.

7 Sawyer SM, Fardy HJ. Bridging the gap between doctors' and patients' expectations of asthma management. J Asthma 2003; 40: 131-138.

8 Rabe KF, Adachi M, Lai CK, et al. Worldwide severity and control of asthma in children and adults: the global asthma insights and reality surveys. J Allergy Clin Immunol 2004; 114: 40-47.

9 Braman SS. The global burden of asthma. Chest 2006; 130: Suppl. 1, 4S-12S.

10 FitzGerald JM, Boulet LP, McIvor RA, et al. Asthma control in Canada remains suboptimal: the Reality of Asthma Control (TRAC) study. Can Respir J 2006; 13: 253-259.

11 Juniper EF, O'Byrne PM, Guyatt GH, et al. Development and validation of a questionnaire to measure asthma control. Eur Respir J 1999; 14: 902-907.

12 Nathan RA, Sorkness CA, Kosinski M, et al. Development of the asthma control test: a survey for assessing asthma control. J Allergy Clin Immunol 2004; 113: 59-65.

13 Schatz M, Sorkness CA, Li JT, et al. Asthma Control Test: reliability, validity, and responsiveness in patients not previously followed by asthma specialists. J Allergy Clin Immunol 2006; 117: 549-556.
14 Liu AH, Zeiger R, Sorkness C, et al. Development and crosssectional validation of the Childhood Asthma Control Test. J Allergy Clin Immunol 2007; 119: 817-825.

15 Murphy KR, Zeiger RS, Kosinski M, et al. Test for respiratory and asthma control in kids (TRACK): a caregiver-completed questionnaire for preschool-aged children. J Allergy Clin Immunol 2009; 123: 833-839.

16 Juniper EF, Svensson K, Mork AC, et al. Measurement properties and interpretation of three shortened versions of the asthma control questionnaire. Respir Med 2005; 99: 553-558.

17 Juniper EF, Gruffydd-Jones K, Ward S, et al. Asthma Control Questionnaire in children: validation, measurement properties, interpretation. Eur Respir J 2010; 36: 1410-1416.

18 Zhou X, Ding FM, Lin JT, et al. Validity of asthma control test for asthma control assessment in Chinese primary care settings. Chest 2009; 135: 904-910.

19 Juniper EF, Chauhan A, Neville E, et al. Clinicians tend to overestimate improvements in asthma control: an unexpected observation. Prim Care Respir J 2004; 13: 181-184.

20 Ko FW, Leung TF, Hui DS, et al. Asthma Control Test correlates well with the treatment decisions made by asthma specialists. Respirology 2009; 14: 559-566.

21 Boulet LP, Phillips R, O'Byrne P, et al. Evaluation of asthma control by physicians and patients: comparison with current guidelines. Can Respir J 2002; 9: 417-423.

22 Raherison C, Abouelfath A, Le Gros V, et al. Underdiagnosis of nocturnal symptoms in asthma in general practice. J Asthma 2006; 43: 199-202.

23 Juniper EF, Bousquet J, Abetz L, et al. Identifying "wellcontrolled" and "not well-controlled" asthma using the Asthma Control Questionnaire. Respir Med 2006; 100: 616-621.

24 van den Nieuwenhof $\mathrm{L}$, Schermer $\mathrm{T}$, Eysink $\mathrm{P}$, et al. Can the Asthma Control Questionnaire be used to differentiate between patients with controlled and uncontrolled asthma symptoms? A pilot study. Fam Pract 2006; 23: 674-681.

25 Thomas M, Kay S, Pike J, et al. The Asthma Control Test (ACT) as a predictor of GINA guideline-defined asthma control: analysis of a multinational cross-sectional survey. Prim Care Respir J 2009; 18: 41-49.

26 O'Byrne PM, Reddel HK, Eriksson G, et al. Measuring asthma control: a comparison of three classification systems. Eur Respir J 2010; 36: 269-276.

27 Koolen BB, Pijnenburg MWH, Brackel HJL, et al. Validation of a web-based version of the Asthma Control Test and Childhood Asthma Control Test. Pediatr Pulmonol 2011 [Epub ahead of print DOI: 10.1002/ppul.21458]. 